\title{
ELETROFLOCULAÇÃO COM DIFERENTES ELETRODOS DE ALUMÍNIO
}

\author{
COMETTI, M.F. ${ }^{1}$; NASCIMENTO, I.L. ${ }^{1}$; MATTEDI, E.V.O ${ }^{1}$; PAIVA, W.V ${ }^{1}$ e ROCHA, \\ S.M.S. ${ }^{1}$
}

${ }^{1}$ Universidade Federal Do Espírito Santo, Departamento de Engenharias e Tecnologia E-mail para contato: sandra.m.rocha@ufes.br

\begin{abstract}
RESUMO - Os óleos e graxas estão comumente presentes em efluentes de oficinas mecânicas, lava-jatos, postos de gasolina, caldeiras, equipamentos movidos a óleo hidráulico, além das mais diversas indústrias que utilizam matérias primas com composição oleosa e manutenção de mecânica pesada. Em geral estes efluentes possuem uma fração de matéria orgânica pouco biodegradável e tóxica, que os torna nocivos para os seres humanos e biota aquática. Necessitando assim, de um tratamento físico-químico para se enquadrar nos limites da legislação federal. Este trabalho objetivou investigar a eficiência de remoção de óleos e graxas e matéria orgânica do efluente oleoso oriundo de uma oficina de mecânica pesada aplicando eletrodos de alumínio do tipo colmeia composta por seis placas, porém um composto por placas maciças e outro por placas perfuradas. Os testes foram realizados em reator eletrolítico em batelada, com tempo de Detenção Hidráulica de 30 min. A redução de Teor de Óleos e Graxas (TOG) foi de $81 \%$ para o eletrodo maciço e $85 \%$ para o eletrodo de placa perfurada. A redução de Demanda Química de Oxigênio (DQO) foi em torno de $30 \%$ para o eletrodo maciço e $67 \%$ para o eletrodo de placa perfurada. O desgaste das placas maciças foi 4 vezes maior que o das placas perfuradas. Permitindo assim concluir que o eletrodo de placa perfurada é mais eficiente para o tratamento do efluente estudado.
\end{abstract}

\section{INTRODUÇÃO}

Com o crescimento populacional em um patamar superior a 7, 5 bilhões de habitantes, a produção em larga escala deixa de ser uma opção e passa a ser a única forma de suprir as necessidades básicas da população. Concomitante a esta explosão industrial ocorreu uma pressão sobre os recursos naturais, principalmente recursos hídricos, quer seja pelo aumento da demanda deste insumo ou pela poluição e deterioração dos mananciais pelos resíduos a eles devolvidos. Portanto, devido a questões ambientais ou econômicas, tem sido dada uma atenção especial para o tratamento, minimização ou reaproveitamento de efluentes líquidos gerados nos diferentes processos industriais. Desta forma, dependendo da disponibilidade de água, o tratamento para o reuso dos efluentes se torna mais interessante devido à redução de custos, visto que o reuso de água residuária passa a ser considerada uma alternativa econômica, ambientalmente racional e eficaz, que permite minimizar a geração de despejos líquidos, assim como o consumo de água. 
Segundo Mancuso e Santos (2003), o desenvolvimento de uma cultura e política que promovam a valorização e conservação de água em todos os setores da sociedade, em conjunto com o reuso consciente e planejado de águas de baixa qualidade (esgotos domésticos e industriais), torna-se o mais moderno e eficaz instrumento de gestão ambiental que subsidia a sustentabilidade dos recursos hídricos.

Nesse contexto, as atividades produtivas cujos efluentes são contaminados basicamente por óleos e graxas tem recebido uma atenção redobrada, porque além de provocar um impacto visual, estes contaminantes são constituídos por estruturas complexas tóxicas e uma fração considerável de difícil biodegradabilidade. No cenário econômico brasileiro, as indústrias que mais se destacam na produção de efluentes oleosos são: as indústrias petroquímicas, empresas de extração de óleo vegetal (soja, milho, etc) e as empresas de beneficiamento de castanhas, além de oficinas mecânicas, lava-jatos, postos de gasolina, casas de caldeiras, além das mais diversas indústrias que utilizam equipamentos movidos a óleo hidráulico e possuem manutenção de mecânica pesada (Silva, 2009).

O tratamento de efluentes oleosos tem dupla importância econômica que são o atendimento às legislações ambientais vigentes para descarte de efluentes e a reutilização da água interna ou e ainda o aproveitamento da fração oleosa recuperada que poderá ser encaminhada tanto para o rerefino como utilizada em subprodutos. De acordo Com Oliveira (1995), este tratamento pode ser através de processos gravitacionais (óleo sob as formas livre ou disperso), centrifugação, flotação ou adsorção associada ao emprego de produtos químicos (óleo emulsionado), extração com solventes e/ou emprego de tratamento biológico (óleo solubilizado), ou ainda a combinação de dois ou mais tratamento.

Dentre os tratamentos supracitados a Eletrofloculação tem recebido destaque devido, entre outros fatores, a disponibilidade facilitada de energia elétrica, compatibilidade ambiental, remoção de partículas coloidais menores, baixo custo operacional e energético e versatilidade de manutenção e operação (Mollah et al., 2004). A operação de eletrofloculação se subdivide em quatro etapas, sendo: geração eletroquímica do agente coagulante, eletrocoagulação, eletrofloculação e eletroflotação (Crespilho e Rezende, 2004).

A eletrofloculação ou eletroflotação foi primeiramente proposta por Elmore, em 1904, visando a recuperação de minerais valiosos de efluentes de extração e beneficiamento destes. A eletrofloculação é um processo simples, em que os poluentes existentes em um efluente líquido são flotados para a superfície através de micro-bolhas de hidrogênio e oxigênio, geradas pela eletrólise da solução aquosa. Portanto, as reações eletroquímicas no catodo e no anodo (eletrodos) são, respectivamente, a liberação de $\mathrm{H}_{2}$ e a liberação de $\mathrm{O}_{2}$.

Segundo Ibrahim et al. (2001), a Eletroflotação apresenta 4 características principais que a diferenciam de outras técnicas de flotação: (a) micro-bolhas extremamente pequenas, de aproximadamente $20 \mu \mathrm{m}$; (b) formação uniforme das micro-bolhas; (c) possibilidade de concentração de micro-bolhas pela variação da densidade de corrente; (d) baixos custos de capital, pequena necessidade de espaço e simples exigências de equipamento, para obtenção da separação em tempos bem inferiores àqueles necessários para a flotação "convencional".

O desempenho de um sistema de eletrofloculação é medido pela eficiência na remoção de poluentes e pelo consumo de energia e/ou reagentes químicos. A remoção de poluentes está 
diretamente relacionada ao tamanho das bolhas geradas, enquanto o consumo de energia está relacionado ao projeto da célula eletrolítica, quer seja em relação aos materiais que compõem a célula, bem como na disposição dos eletrodos, na distância entre as placas, bem como nas condições operacionais como densidade de corrente, condutividade da solução, dentre outras. A variação do tamanho de bolhas depende do material e da condição superficial dos eletrodos, do espaçamento entre as placas, bem como do pH da solução e da intensidade de corrente.

Segundo Rangel (2008), a eletrocoagulação envolve a formação in situ de íons por eletrólise, utilizando anodos metálicos consumíveis ( $\mathrm{Al}$ e $\mathrm{Fe}$ ) para geração de íons metálicos próximo à superfície anódica. Tal geração de íons é seguida pela concentração eletroforética de particulados ao redor do anodo. Os íons são atraídos pelos particulados, neutralizando suas cargas e possibilitando sua coagulação. As bolhas de hidrogênio, liberadas pelo catodo, unem-se às partículas floculadas, permitindo sua ascensão e remoção da solução. No ânodo ocorre a oxidação do alumínio conforme a Equação 1, bem como a evolução do oxigênio nas Equações 2 e 3.

$$
\begin{aligned}
& A l \rightarrow \mathrm{Al}_{(a q)}^{3+}+3 e^{-} \\
& 2 \mathrm{H}_{2} \mathrm{O} \rightarrow \mathrm{O}_{2}+\mathrm{H}^{+} 0020+2 e^{-} \\
& 2 \mathrm{OH}^{-} \rightarrow \mathrm{O}_{2}+\mathrm{H}^{+}+2 e^{-}
\end{aligned}
$$

O cátion gerado em 1 forma o agente coagulante, de acordo com a Equação 4.

$$
\mathrm{Al}^{3+}{ }_{(a q)}+3 \mathrm{H}_{2} \mathrm{O} \rightarrow \mathrm{Al}(\mathrm{OH})_{3}+3 \mathrm{H}_{(a q)}^{+}
$$

Pode haver a seguinte reação (Fornari, 2007)

$$
n \mathrm{Al}(\mathrm{OH})_{3} \rightarrow \mathrm{Al}_{n}(\mathrm{OH})_{3 n}
$$

Os agentes coagulantes formados nas Equações 4 e 5 são os responsáveis por desestabilizar o óleo disperso e coagulá-los.

Paralelamente, há a evolução do hidrogênio no cátodo (Gobbi, 2013):

$$
2 \mathrm{H}_{2} \mathrm{O}+2 e^{-} \rightarrow \mathrm{H}_{2}+2 \mathrm{OH}^{-}
$$

São as microbolhas de $\mathrm{O}_{2}$ nas equações 2 e 3 e de $\mathrm{H}_{2}$ na equação 6 que são responsáveis pela eletroflotação. Processo no qual há o carreamento das partículas coaguladas.

Durante a operação do reator ocorre a passivação no cátodo, no qual há excesso de $\mathrm{OH}^{-} \mathrm{e}$ consequente formação de um filme muito fino na superfície do eletrodo. $\mathrm{O}$ resultado é o decaimento da eficiência da célula eletrolítica. Uma alternativa para diminuir o efeito de passivação é utilizar um inversor de polaridade. Deste modo, a cada intervalo de tempo prédeterminado, o ânodo transforma-se em cátodo e vice-versa.

O objetivo do trabalho é investigar a eficiência de redução de DQO e TOG em efluente oleoso oriundo de uma oficina de mecânica pesada utilizado eletrodos de alumínio construído no 
tipo colmeia com seis placas, se diferenciando por um conter placas maciças e o outro placas perfuradas.

\section{MATERIAIS E MÉTODOS}

Para a realização dos testes foi utilizado um efluente oleoso proveniente de um oficina de mecânica pesada, coletado em uma empresa mineradora no estado do Espírito Santo. Em cada etapa do experimento, foram utilizados $3,5 \mathrm{~L}$ do efluente.

Usou-se dois arranjos de eletrodos, um construído com placas maciças de alumínio e o outro com placas perfuradas, cada eletrodo do tipo colméia era formado por 6 placas, sendo três ânodos e três cátodos, alternados entre si, de dimensões $13 \mathrm{~cm} \mathrm{X} 6,5 \mathrm{~cm} \times 0,2 \mathrm{~cm}$, em que o eletrodo de alumínio perfurado contém 12 furos de diâmetro $10 \mathrm{~mm}$ espaçados lateralmente de $6,72 \mathrm{~mm}$ e diagonalmente de $8,5 \mathrm{~mm}$ (Figura 1). Os eletrodos foram posicionados verticalmente no reator eletrolítico.

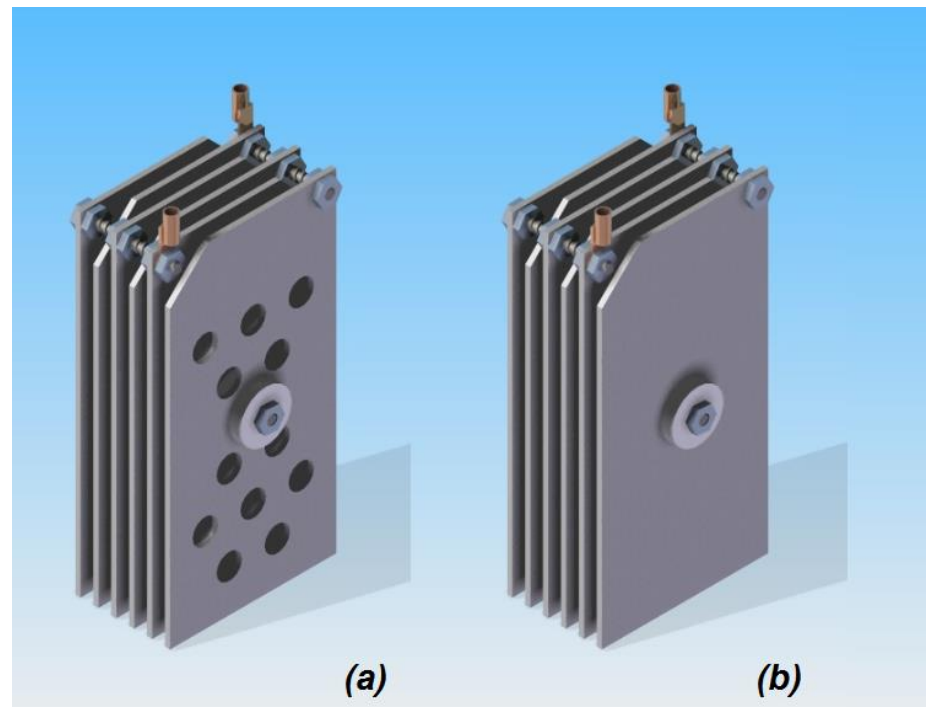

Figura 1 - a) Eletrodo de alumínio perfurado; b) Eletrodo de alumínio maciço Fonte: elaborado pelo autor.

Na Figura 2 pode se observar o sistema operacional utilizado na realização dos testes. O sistema operacional é constituído por: (1) eletrodo formado por seis placas metálicas conforme descrito anteriormente; (2) célula eletrolítica com capacidade para quatro litros, na qual coloca-se o efluente em regime de batelada. Há uma torneira para coletas intercaladas do efluente, uma tampa com dois respiradores e dois orifícios para passagem dos fios que conectam o inversor ao eletrodo; (3) inversor de polaridade; (4) fonte utilizada com tensão de $12 \mathrm{~V}$. 


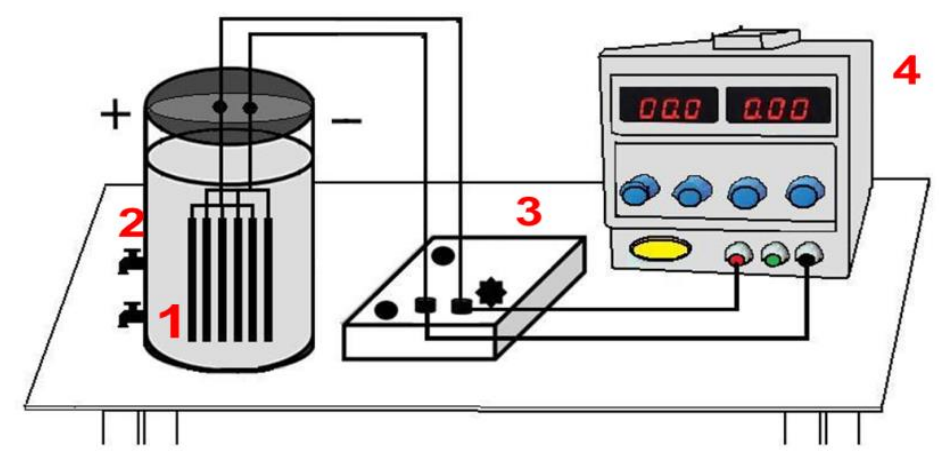

Figura 2 - Desenho esquemático do sistema de eletrólise Fonte: Gobbi (2013).

Para a realização dos experimentos conectou-se os eletrodos à fonte por intermédio do um inversor de polaridade, programado para a cada dez segundos alternar o sentido da corrente. $\mathrm{O}$ objetivo é minimizar o efeito de passivação no cátodo - posto que cátodo e ânodo alternam-se entre si - e consequentemente aumentar a durabilidade do eletrodo, conforme Crespilho et al. (2004). O alternador por sua vez foi conectado a uma fonte de corrente contínua submetida a uma tensão de $12 \mathrm{~V}$. Foram colocados na célula eletrolítica 3,5 L de efluente. Nos tempos 0, 5, 10, 20 e 30 minutos eram retirados do reator $350 \mathrm{ml}$ de amostra para realização das analises de forma a se determinar a eficiência do reator em função do tempo de eletrólise. Os parâmetros em questão são: Demanda química de oxigênio (DQO) e teor de óleos e graxas (TOG).

\section{RESULTADOS E DISCUSSÕES}

A Figura 3 apresenta os dados de eficiência de remoção de DQO em função do tempo de eletrólise, para a realização dos testes a intensidade de corrente foi mantida em 12 volts e o pH inicial da amostra era de 6,8.

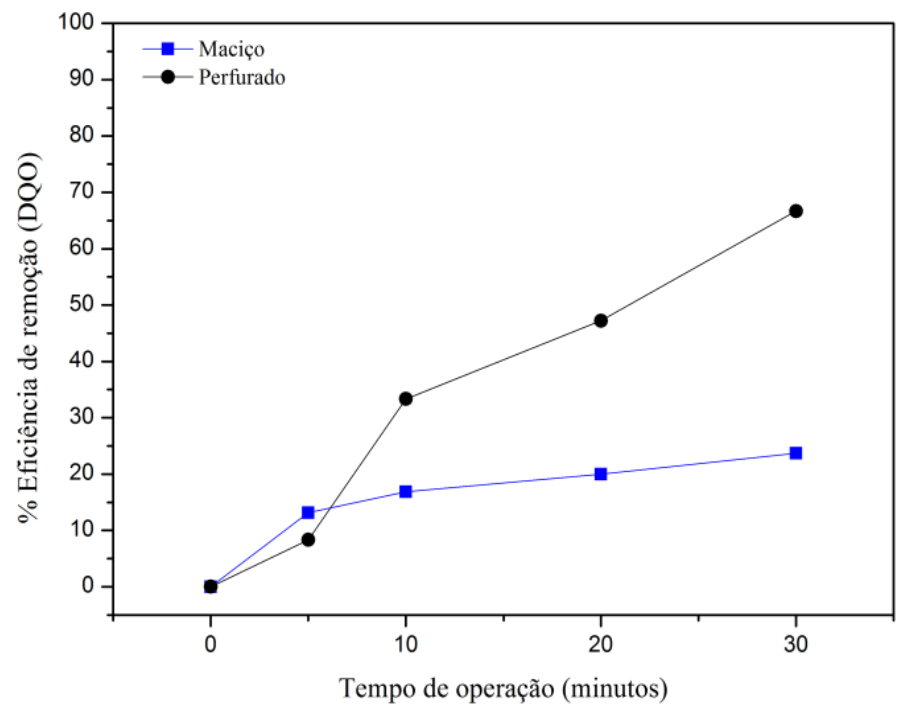

Figura 3 - Efeito do tempo em relação a remoção de DQO. Fonte: elaborado pelo autor. 
A Figura3 mostra que o eletrodo de alumínio maciço apresentou uma melhor eficiência na remoção de matéria orgânica nos primeiros cinco minutos de operação do reator, quando comparado ao eletrodo de alumínio perfurado. Este fenômeno pode ser explicado de acordo com Torem at al. (2005), que verificou que uma maior área efetiva no eletrodo propicia a maior formação de $\mathrm{H}_{2(\mathrm{~g})}$ no cátodo e flotação mais intensa da matéria orgânica presente no efluente, porém com o tempo de eletrólise, a área mais próxima do seio da solução foi desgastada, diminuindo a produção de hidróxido de alumínio naquela região. Como a partir deste momento a maior produção passou a ser no centro do eletrodo, o tempo para despendimento dos íons no eletrodo maciço foi maior quando comparado às placas perfuradas de forma que a eficiência de remoção da matéria orgânica foi maior para este efluente visto que ao final dos 30 minutos de operação, a redução de DQO do eletrodo maciço foi de pouco mais de $20 \%$ e para o eletrodo perfurado próximo a 70\%. A Figura 3 ainda permite constatar que para ambos os eletrodos a inclinação das retas entre os tempos de eletrólise de 5 e 10 minutos é maior comparada aos demais intervalos de tempo. Esta inclinação pode ser explicada devido a maior concentração de matéria orgânica no inicio do processo. Após dez minutos de detenção a concentração torna-se menor, o que diminui o rendimento dos eletrodos.

De forma a se verificar a eficiência de remoção de óleos e graxas do efluente oleoso, também foram feitas análises de Teor de Óleos e Graxas (TOG) para o efluente submetido à eletrólise com ambos os eletrodos, as curvas resultantes destas analises serão apresentadas na Figura 4.

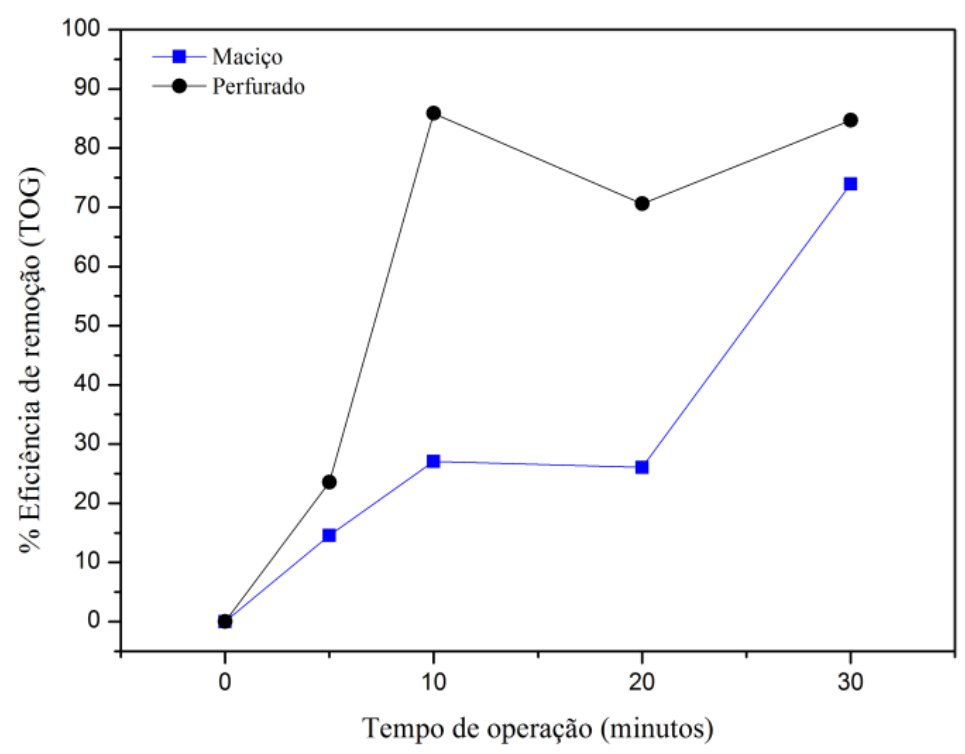

Figura 5 - Efeito do tempo em relação a remoção de TOG. Fonte: elaborado pelo autor.

Durante o processo de remoção de óleos e graxas, no ânodo há geração eletroquímica do elemento $\mathrm{Al}^{3+}$ presente no agente coagulante $\mathrm{Al}(\mathrm{OH})_{3}$, o qual é responsável pela coagulação das gotículas de óleos e graxas. Paralelamente, no cátodo, há a geração de microbolhas de hidrogênio, responsáveis por carrear as gotículas coaguladas. No decorrer do processo de operação do reator nota-se um crescimento acentuado entre os minutos 0 e 10 seguido por uma queda de eficiência de 
remoção. O decaimento decorre do mento do $\mathrm{pH}$ no meio, pois em $\mathrm{pH}$ alcalino, a coagulação das gotículas de óleo diminui, assim os valores do TOG diminuem também (Mostefa e Tir, 2008). As microbolhas formadas durante o processo de eletrofloculação agregam-se umas as outras até adquirirem volume significativo e se desprenderem da placa. Por diferença de densidade, as bolhas movimentam-se ascendentemente, promovendo o carreamento de óleos, graxas e excedentes.

A Figura 4 mostra que até os cinco primeiros minutos de eletrólise a eficiência de separação de óleos e graxas é bem próxima para os dois eletrodos. Outra constatação ao se analisar a figura é que o tempo de detenção hidráulica (TDH) para a remoção de óleos e graxas do efluente em estudo é de 10 minutos para o eletrodo de placas perfuradas e de 30 minutos para o maciço. Pois em 10 minutos de operação a eficiência de remoção para o eletrodo de placa perfurado atingiu seu maior valo, vindo a cair depois devido à baixa concentração de óleos e graxas no efluente para ser removido. Para o eletrodo maciço isto não foi observado, a maior eficiência de remoção para este caso foi entre 20 e 30 minutos de eletrólise, o que exige um TDH para tratamento do efluente em estudo 3 vezes maior que o TDH do perfurado. Ao final dos 30 minutos de eletrólise a eficiência dos dois eletrodos estudados está em torno de $80 \%$. Porém a analise em relação à eficiência de remoção em função TDH mostra que o eletrodo de placas perfuradas é consideravelmente mais eficiente que o eletrodo maciço

\section{CONCLUSÃO}

O tratamento do efluente oleoso oriundo da lavagem de peças, componentes e motores de uma oficina de vagões pode ser realizado de forma eficiente pela técnica de eletrofloculação conforme dados obtidos neste trabalho, em escala de bancada, que obtiveram valores considerados satisfatórios comparados com a literatura. Tal constatação refere-se a valores superiores, a $80 \%$ quanto à redução de TOG e 50\% da DQO, em um curto tempo operacional (30 minutos);

O eletrodo de alumínio com placas perfuradas apresentou maior eficiência na remoção de matéria orgânica e óleos e graxas.

Porém a técnica de eletrofloculação aplicada isoladamente não foi capaz de enquadrar o efluente oleoso segundo a resolução CONAMA N ${ }^{\circ} 430 / 2011$, que trata das Condições e Padrões de Lançamento de Efluentes, no parâmetro de óleos e graxas para óleos minerais, pois a concentração mínima permitida é de $20 \mathrm{mg} / \mathrm{L}$, e o resultado obtido com eletrodo de alumínio com placas perfuradas neste trabalho foi de $40 \mathrm{mg} / \mathrm{L}$, logo faz-se necessário de algum tratamento subsequente, ou a adição de eletrólitos ao efluente para garantir o enquadramento na legislação ambiental.

\section{REFERÊNCIAS.}

CRESPILHO, F. N.; SANTANA, C. G.; REZENDE, M. O. O. Tratamento de efluente de indústria de processamento de coco utilizando eletroflotação. Química Nova, vol 27, n 3, p. 387-392, 2004.

FORNARI, M. M. T. Aplicação da técnica de eletro-floculação no tratamento de efluentes de curtume. 2007. 112 f. Dissertação (Mestrado em Engenharia Química) - Universidade Estadual do Oeste do Paraná, Centro de Engenharias e Ciências Exatas, Toledo. 
GOBBI, L.C.A. Tratamento de água oleosa por eletrofloculação. Dissertação (mestrado). Universidade Federal do Espírito Santo. São Mateus, 2013.

Ibrahim, M.Y., Mostafa, S.R., Fahmy, M.F.M., Hafez, A.I., 2001. Utilization of electroflotation in remediation of oily wastewater. Separation Science and Technology 36, 3749-3762.

MANCUSO, P. C. S., SANTOS, H. F., (editores). Reuso de água. Barueri, São Paulo. Editora Manole, 2003.

MOLLAH, M.Y.A.; MORKOVSKY P.; GOMES, J. A. G.; KESMEZ, M.; PARGA, J.; COCKE, D. L., Fundamentals, present and future perspectives of electrocoagulation. Journal of Hazardous Materials, v. B114, p. 199-210, 2004.

MOSTEFA, N. M.; TIR, M., Coupling flocculation with electroflotation for waste oil/water emulsion treatment. Optimization of the operating conditions. Desalination, v. 161, p. 115-121, 2004.

OLIVEIRA, R.C.G., Estudo de Variáveis Interfaciais e Operacionais na Flotação de Óleo por Gás Dissolvido. Dissertação de Mestrado, COPPE/UFRJ, Rio de Janeiro, 1995.

RANGEL, R.M. - Modelamento da eletrocoagulação aplicada ao Tratamento de águas oleosas provenientes das indústrias Extrativas, Tese de Doutorado, Engenharia Metalúrgica e de Materiais, PUC - Rio de Janeiro, 2008.

SILVA, S.R. - Tratamento De Efluentes De Indústria De Beneficiamento De Coco. Dissertação de mestrado. Programa de Pós-Graduação em Engenharia Química da Universidade Federal de Alagoas - Maceió 2009.

TOREM, M. L.; CUNHA, F. O.; CASQUEIRA, R. G., Eletroflotação aplicada a remoção de metais pesados contidos em efluentes líquidos. Tec. Metalurgia e Materiais. v. 1, n.4 , p. 40-46, 2005. 